\title{
The role of simulation in teaching pediatric resuscitation: current perspectives
}

This article was published in the following Dove Press journal:

Advances in Medical Education and Practice

3I March 2015

Number of times this article has been viewed

\author{
Yiqun Lin' \\ Adam Cheng ${ }^{2}$ \\ 'KidSIM-ASPIRE Simulation Research \\ Program, Alberta Children's Hospital, \\ University of Calgary, Calgary, AB, \\ Canada; ${ }^{2}$ KidSIM-ASPIRE Research \\ Program, Department of Pediatrics, \\ Division of Emergency Medicine, \\ University of Calgary, Alberta \\ Children's Hospital, Calgary, AB, \\ Canada
}

\begin{abstract}
The use of simulation for teaching the knowledge, skills, and behaviors necessary for effective pediatric resuscitation has seen widespread growth and adoption across pediatric institutions. In this paper, we describe the application of simulation in pediatric resuscitation training and review the evidence for the use of simulation in neonatal resuscitation, pediatric advanced life support, procedural skills training, and crisis resource management training. We also highlight studies supporting several key instructional design elements that enhance learning, including the use of high-fidelity simulation, distributed practice, deliberate practice, feedback, and debriefing. Simulation-based training is an effective modality for teaching pediatric resuscitation concepts. Current literature has revealed some research gaps in simulation-based education, which could indicate the direction for the future of pediatric resuscitation research.
\end{abstract}

Keywords: simulation, pediatric resuscitation, medical education, instructional design, crisis resource management, health care

\section{Introduction}

Dealing with acute pediatric emergencies can be challenging. Compared to adults, children have anatomical and physiological differences that place additional demands on health care providers when caring for critically ill children. Pediatric health care providers require training opportunities to acquire the knowledge and skills to appropriately manage children with critical illness and cardiac arrest. Pediatric resuscitation events are relatively rare, and trainees often have few opportunities to master procedures on real patients. Many pediatric trainees finish their training lacking sufficient procedural proficiency and resuscitation expertise in the care of critically ill children. ${ }^{1}$

In the past decade, simulation has been integrated into the fabric of health care education across various specialties. The use of simulation as an educational tool provides a risk-free environment for both patients and pediatric trainees to address pertinent issues related to resuscitation training. There is a growing body of simulation literature related to pediatric resuscitation. This article describes the application of simulation for teaching pediatric resuscitation and discusses instructional design issues related to enhancing simulation-based education (SBE) for pediatric resuscitation.

\section{Literature search and study selection}

We searched both the Medline database and Google Scholar for the relevant articles. The search included terms related to the topic (simulat*, mannequin, etc) and content (resuscitation, procedur*, airway*, life support, etc). We then filtered all studies related to pediatric resuscitation and supplemented the search by examining the entire 
reference list of several review articles..$^{2-4}$ We included both observational studies and studies with experimental designs (eg, randomized trials).

\section{Simulation for pediatric resuscitation training}

Simulation has been used to teach neonatal resuscitation, pediatric advanced life support, advanced airway management, procedural skills training, and crisis resource management (CRM) training. In the following section, we describe the evidence supporting the use of SBE for each of these areas of pediatric resuscitation.

\section{Neonatal resuscitation}

Standardized neonatal resuscitation training opportunities such as the Neonatal Resuscitation Provider (NRP) course have helped to disseminate internationally recognized guidelines for neonatal care. Previous versions of NRP training consisted of lectures, videos, and skill stations where trainees practiced individual procedural skills on low fidelity mannequins. When delivered in this manner, providers attending NRP training demonstrated retention of knowledge and procedural skills for only 6 months. ${ }^{5}$ The more recent versions of NRP have integrated SBE with a focus on the behavior and team performance during neonatal resuscitation. ${ }^{6}$

Studies assessing the impact of simulation-based neonatal resuscitation education have produced variable results. ${ }^{4} \mathrm{Cava}-$ leiro et $\mathrm{al}^{7}$ reported no significant differences in acquisition of neonatal resuscitation-related knowledge after simulationbased training compared with self-study. However, the study was limited by the use of a single simulation session, and only cognitive skills were assessed. In a study by Lee et al, ${ }^{8}$ traditional NRP with an extra simulation-based training session significantly improved performance and confidence levels when compared with the traditional NRP course alone. Weiner et $\mathrm{al}^{9}$ showed that self-study with a simple low-fidelity mannequin was not superior to the standard NRP course (with standard neonatal mannequin) as measured by nurses' mega code performance, cognitive skills, and self-confidence. Curran et a $1{ }^{10}$ compared "booster" simulation-based neonatal resuscitation training in a pre- and posttest study design, suggesting that SBE was not more effective than an instructional video for neonatal resuscitation education.

Most of the studies reported learning outcomes (ie, knowledge test, performance skill), while studies using clinical outcome measures are limited. Draycott et al ${ }^{11}$ developed a simulation-based training intervention for obstetrical and neonatal teams. Following the introduction of the course, incidence of hypoxic-ischemic encephalopathy (HIE) decreased from 27.3 to 13.6 per 10,000 births. Although other factors might have affected the incidence of HIE, and these factors were not adjusted in the analysis, the study still demonstrated the potential benefit of simulationbased training on actual patient outcomes. Given the small number of studies, small sample sizes, inconsistent results, and lack of clinical outcomes in most studies, there is still insufficient evidence to clearly demonstrate that use of SBE improves translational outcomes from neonatal resuscitation training. The continued use of SBE for standardized neonatal training presents an opportunity to help clarify the relationship between simulation-based training and desired learning outcomes.

\section{Pediatric advanced life support}

Simulation has been incorporated into pediatric emergency medicine (PEM) and pediatric critical care training curricula in many different countries. Based on a survey in the US and Canada in 2013, 63\% of PEM fellowship programs have incorporated high-fidelity simulation (HFS) into PEM training. ${ }^{12}$ For pediatric critical care training, a multi-institutional "boot camp" orientation for first-year pediatric intensive care unit (PICU) fellows was developed to cover the most common crises. ${ }^{13}$ Learners participated in simulation sessions covering airway management, vascular access, sepsis, resuscitation, traumatic brain injury, and delivery of bad news. A follow-up survey revealed that boot camp training was effective in improving future clinical performance. ${ }^{13}$ Simulation-based educational programs have also been shown to improve the self-reported knowledge, skills, and comfort of intensive care unit nursing staff when caring for critically ill children. ${ }^{14}$ Stocker et al ${ }^{15}$ reported similar findings for an embedded simulation-based training curriculum in the PICU. While these programs demonstrate potential benefits for SBE, they focus on self-reported outcomes at the provider level (ie, satisfaction, confidence, comfort), with no assessment of clinical performance or actual patient outcomes.

The Pediatric Advanced Life Support (PALS) course has become the gold standard for pediatric resuscitation training, with integrated components of SBE in the form of procedural skills training and core case scenarios. While providers taking the course typically acquire knowledge of the essential elements of resuscitation management, the knowledge often decays significantly over a 12 month period. ${ }^{16}$ Some studies have examined resuscitation performance when using 
high- versus low-fidelity simulators during the course. Coolen et $\mathrm{al}^{17}$ compared HFS training to conventional PALS (low-fidelity), and demonstrated higher clinical performance scores in the high-fidelity group. In a study by Donoghue et $a l,{ }^{18}$ pediatric residents were randomized to either HFS training or standard mannequin for management of pediatric cardiac arrest. After training, the satisfaction ${ }^{19}$ and clinical performance of the HFS group was significantly superior in comparison to the standard mannequin group. These results suggest that SBE is a promising and effective educational modality for teaching management of pediatric resuscitation events. Future work should identify how to best integrate SBE into existing training curricula for acute care training programs, and to explore how to provide sufficient opportunity for practicing professionals to maintain and enhance their resuscitation skills.

\section{Airway management}

Although airway management skills have been built into pediatric residency training curriculum in Canada and the United States, individual trainee levels of competency related to airway skills have been suboptimal. ${ }^{20}$ Pediatric and PEM training programs have seen widespread uptake of SBE, particularly for training in intubation and for teaching difficult airway management skills. ${ }^{12,20}$

Several studies have examined the use of SBE for teaching airway management skills in pediatrics. In a simulation-based randomized trial, ${ }^{21}$ airway management and teamwork training with HFS resulted in improved global competency scores and a reduction in harmful behaviors. Nishisaki et a ${ }^{22}$ demonstrated that "just-in-time" simulated intubation training did not improve the residents' first attempt or overall success with tracheal intubation on real pediatric patients. However, a later prospective observational study ${ }^{23}$ conducted by the same research group revealed the clinical performance of a team with more than two simulation-trained members was significantly better than a team with less than two simulationtrained members. Lastly, Finan et $\mathrm{al}^{24}$ reported that improved neonatal intubation skills following a simulation-based training session did not effectively transfer to the clinical environment. Most of the simulation-based studies for airway management were limited with nonrandomized designs or small sample sizes. The inconsistency in results suggest that simulation training might lead to improved educational outcomes, but there is a gap when it comes to transferring skills from simulated scenarios to the real clinical world. This may be related to inadequate realism of simulators for airway training, ${ }^{25}$ the instructional design of the simulation-based educational intervention, or other variables that influence clinical outcomes (eg, institutional protocols). Future work should identify the best way to teach airway skills using SBE that promote transfer of acquired skills to the real clinical environment.

\section{Cardiopulmonary resuscitation}

Cardiopulmonary resuscitation (CPR) is the most important treatment for cardiac arrest. High quality CPR has a positive impact on outcomes from cardiac arrest. ${ }^{26,27}$ As such, improved CPR training has the potential to have a significant positive impact on survival from pediatric cardiac arrest. ${ }^{28}$ Simulation is a key tool for teaching CPR skills. ${ }^{29}$ In North America, American Heart Association Life support training courses, such as Basic Life Support (BLS) and PALS have become gold standard for CPR training. However, despite these courses, health care providers still struggled to provide high quality CPR. ${ }^{30,31}$ Research exploring the use of SBE for teaching CPR skills has shifted from "whether or not to use simulation" to "how to use simulation".

Several promising educational innovations that could assist in improving the quality of CPR have recently been identified. First, the implementation of distributed practice, or CPR training conducted at intermittent and regular points in time, improves acquisition and retention of CPR skills in pediatric health care providers. ${ }^{32,33}$ Second, the implementation of real-time automated CPR feedback devices during training has been shown to improve CPR quality and compliance with guidelines. ${ }^{30,34}$ Lastly, structured performance debriefings have been shown to improve the quality of CPR and patient outcomes. ${ }^{35,36}$ These studies provide compelling evidence to support the use of SBE for teaching CPR skills. Resuscitation councils should provide guidance to support the implementation of simulation-based CPR training with real-time feedback that is provided in a distributed fashion to health care providers most likely to care for patient suffering from cardiac arrest.

\section{Other procedural skills}

Simulation has been used as a training tool to improve procedural skills related to pediatric resuscitation, such as chest tube thoracotomy, ${ }^{37,38}$ central line placement, ${ }^{39}$ intraosseous (IO) line placement, ${ }^{40,41}$ and peripheral intravenous catheter insertion. ${ }^{42}$ Al-Qadhi et $\mathrm{al}^{37}$ recently developed a pediatric chest tube insertion task trainer and piloted it in pediatric trainees with high trainee satisfaction. Gupta and Ramasethu $^{38}$ developed an inexpensive infant/neonate chest tube insertion model and found that all residents had a significant 
improvement in knowledge, comfort, and skills scores after SBE sessions, with retention of skills after 1 month. Gerard et $\mathrm{a}^{40}$ demonstrated that family medicine trainees who received 2 hours procedural training using HFS improved their performance of bag-mask ventilation and IO insertion, with retention of skills at 6 months follow-up. In another study, ${ }^{42}$ pediatric residents who received SBE were more successful in peripheral intravenous catheter and lumber puncture than those taught with other methods. Lastly, Mikrogianakis et $\mathrm{al}^{41}$ reported the use of "telesimulation" (ie, remote web-based access to an instructor) as an innovative tool to teach novice learners IO needle insertion. Telesimulation offers the potential for teaching procedures in resourcelimited areas of the world and was shown to improve learners' knowledge, self-reported confidence, and comfort levels. In summary, procedural skills that used to be taught with the "see one, do one, teach one" approach are now being taught with a more educationally sound "see one, simulate a lot, do one, teach one" approach to learning.

\section{Crisis resource management training}

CRM is team training that focuses on behavioral skills, resource utilization, communication, leadership, and teamwork. A recent review article by Cheng et $\mathrm{al}^{43}$ described how simulation training can be used to teach CRM principles in the pediatric acute care context, including simulation scenario design, effective debriefing, and assessment of CRM performance during simulation-based training. A growing body of evidence has supported the use of simulation in CRM teaching. ${ }^{44-48}$

For example, Thomas et $\mathrm{al}^{44}$ added a simulation-based team training module to the NRP course and compared it with standard NRP. Trainees receiving extra team training demonstrated more frequent team behaviors such as information sharing, inquiry, assertion, vigilance, and workload management in simulated neonatal resuscitation. In another cohort study, Gilfoyle et $\mathrm{al}^{45}$ developed a workshop to teach leadership skills in simulated pediatric resuscitation scenarios. Pediatric residents acquired leadership skills following the simulation-based educational intervention as measured by an observational checklist and self-reported survey. In a simulation-based training course, Figueroa et $\mathrm{al}^{46}$ used common postcardiac surgical emergency scenarios to teach teamwork and communication in a pediatric cardiovascular intensive care unit multidisciplinary team. A significant increase in the application of teamwork concepts by trainees was observed both immediately after training and 3 months later. In a recent study by Bank et al ${ }^{47}$, a 4-hour simulation-based workshop on pediatric CRM was developed, and pediatric residents improved their self-perception and performance on a video assessment task after the simulation-based educational intervention. In a study ${ }^{48}$ examining the effect of a 1-hour simulation-based CRM training session embedded in PALS training, CRM trained participants improved their time to the critical initial steps of pediatric resuscitation (ie, placement of monitor leads, calling for help, IV access, pulse check) and CRM performance as measured by the Ottawa Global Rating Scale.

These studies suggest that simulation-based CRM training is effective in promoting the acquisition of key CRM behaviors that impact outcomes from pediatric resuscitation. Future research could consider assessing CRM in different team structures and testing team performance in the actual workplace (in situ simulation).

\section{Instructional design elements for simulation-based resuscitation education}

As SBE has been established as an effective educational modality for both adult ${ }^{49}$ and pediatric ${ }^{2}$ disciplines, the logical next question is: "How should SBE be optimally designed to enhance learning outcomes?" Effective instructional design is a critical component of SBE that pediatric resuscitation educators should consider when utilizing simulation-based resuscitation training. A recent systematic review identified ten different instructional design features for SBE and highlighted the relative benefit of each feature for various types of learning outcomes. ${ }^{50}$ In the following section, we will describe several instructional design features identified from our literature review that have been studied in the context of pediatric simulation-based resuscitation education.

\section{High-fidelity simulation}

One of the approaches to improving pediatric resuscitation education is the use of HFS. Based on the behaviorist orientation to learning described by Merriam et al, ${ }^{51}$ learning environments have a significant influence on learning and behavior change. ${ }^{52}$ This theory suggests that if teaching and training takes place when and where the knowledge and skill will be used, it will help to enhance the automatic transfer of learning to the real clinical environment. The educator's role in this framework is to provide an environment that simulates reality for the learner to elicit a specific response. ${ }^{53}$

Several studies comparing the use of high- versus lowfidelity simulation for pediatric resuscitation training have been conducted. A systematic review by Cheng et $\mathrm{al}^{2}$ included 
seven studies comparing high versus low physical realism simulators as the primary training modality. The pooled effect favors HFS with a small effect size for learner's reaction (ie, satisfaction, self-perception) and nontime skills. HFS was also found to be superior to low-fidelity simulation in knowledge and time skills, but none of the findings were statistically significant.

Three studies compared HFS with low-fidelity simulation in neonatal resuscitation training. Campbell et $\mathrm{al}^{54}$ demonstrated in a randomized trial that residents trained with highfidelity mannequins had a trend to greater improvement in written examination scores (ie, knowledge) and shorter times to intubation (time skills). As an educational experience (ie, learner reactions), HFS training was rated significantly higher compared to low-fidelity training. Thomas et $\mathrm{al}^{55}$ explored the effect of team training and HFS on teamwork behavior and neonatal resuscitation performance, and found that low- and high-fidelity trained groups exhibited more frequent teamwork behaviors, better workload management, and completed resuscitation more quickly than the low fidelity and nonteam training group. However, the investigators failed to demonstrate a significant difference between high- and low-fidelity training for NRP performance (ie, nontime skills) and resuscitation duration (ie, time skills). Another small randomized trial ${ }^{56}$ also suggested that high-fidelity NRP training was not superior to low-fidelity equipment as measured by NRP performance score (ie, nontime skill).

Three studies were identified that compared high versus low fidelity simulation for PALS training. In a multicenter trial by Cheng et al, ${ }^{57}$ an interprofessional health care team participated in two cardiopulmonary arrest scenarios. In this study, the simulator's physical realism did not have a significant effect on acquisition of knowledge, clinical performance, or team leader's behavioral performance. In a different single-center study, trainees receiving HFS training were superior in clinical performance compared with those receiving standard mannequin training ${ }^{18}$ and rated the scenario to be "highly realistic" ${ }^{19}$ In nursing education, one study ${ }^{58}$ reported that those who participated in HFS perceived the simulation to have a greater impact on problem-solving ability, with the learning time being more active and productive when compared to low-fidelity simulation. Bultas et $\mathrm{al}^{59}$ compared the effectiveness of HFS with traditional mannequins as a teaching strategy for nursing education in the Pediatric Early Assessment, Recognition and Stabilization (PEARS) course. HFS was not found to be superior to traditional mannequins as measured by the PEARS written test score and the Mayo high performance teamwork scale, ${ }^{60}$ but was found to be significantly better when assessing clinical skills for acute care.

Based on the current literature comparing high- vs low-fidelity simulation, we still do not have overwhelming evidence to support the use of HFS over low-fidelity simulation. Currently, most of the current literature focuses on high- versus low-technology mannequins, as opposed to the relative impact of the various types of fidelity in different learning contexts. The importance of the fidelity is dependent on multiple factors, including types of fidelity (physical, conceptual, emotional), learner type (novice vs experienced), and learning objectives (cognitive, affective, psychomotor). As such, further work to explore the effect of conceptual or emotional fidelity on different types of learners, and in different learning contexts, is essential to help define the optimal use of HFS. Educators should give consideration to these factors when deciding what degree of fidelity is required to achieve the desired learning outcomes. What is clear is that learners have a very favorable view of HFS, and feel that high-fidelity training helps to promote learner engagement in the simulated experience. While the jury is still out on the benefits of using HFS as it relates to transfer to outcomes in real patients, pediatric simulation educators should still consider using HFS if the resources are available.

\section{Distributed practice}

Distributed practice refers to learning spread over a period of time. Theoretically, teaching in small proportions dispersed over time is better with respect to knowledge and skill retention compared with massed delivery. ${ }^{61}$ This is explained by a two-factor model consisting of contextual variability and study-phase retrieval. ${ }^{62}$ Based on contextual variability, slight changes in different training sessions can be automatically stored in memory. These contextual elements might be used as retrieval cues, which lead to improved recall. For mass delivery, the difference in context is too small to function as retrieval cues. Study-phase retrieval states that the first presentation of an item is retrieved at the time of the second presentation. This supports the notion of distributed practice, where learners have multiple opportunities for retrieval of information that is presented during the initial exposure. ${ }^{62}$

Distributed practice has been used effectively for CPR training. Niles et al ${ }^{32}$ reported the use of "rolling refreshers", or dispersed low-dose training sessions interposed during routine clinical duties, on CPR performance for PICU staff. The study showed that refreshed staff performed much better than infrequently refreshed staff measured by time to achieve excellent CPR (adequate depth, rate, and residual 
leaning force). The efficacy of "high frequency, low dose training" has also been demonstrated by the same research group. Sutton et $\mathrm{al}^{33}$ reported that frequent and brief low-dose bedside CPR booster training (1-minute CPR training) is effective in improving CPR skill retention in BLS-certified pediatric health care providers compared to a control group who received no bedside training.

Distributed practice has also shown potential in pediatric advanced life support training. Kurosawa et al ${ }^{63}$ compared standard PALS with "PALS-reconstructed", which deconstructs the training into six 30-minute in situ simulation sessions dispersed over 6 months. The PALS-reconstructed group had significantly higher clinical performance when compared to the standard PALS group. The effect of the PALSreconstructed group may have been related to a combination of several instructional features, such as distributed practice, the use of in situ simulation, and multidisciplinary training.

The evidence supporting distributed practice for pediatric airway management training is less convincing. Nishisaki et $\mathrm{al}^{22}$ failed to repeat the effect of distributed refresher training on pediatric intubation in the intensive care unit environment by residents. In a recent randomized trial on neonatal intubation training for medical students during clerkship, Ernst et $\mathrm{al}^{64}$ failed to demonstrate a significant difference between training dispersed over 4 weeks and training in 4 consecutive days during a 6 -week period. This could be explained by 6-week clerkship not being long enough to differentiate skill retention.

Overall, the use of distributed practice has been shown to improve psychomotor skill acquisition and retention. Further work in this area should include exploring how distributed and frequent the practice for specific skills should be, and whether or not the context of practice has an influence on learning outcomes.

\section{Deliberate practice}

Deliberate practice was initially used by Ericsson ${ }^{65}$ in instructional science research and has since then been adapted in medical training. The main components of deliberate practice include a well-defined objective at an appropriate difficulty level, repetitive practice, and immediate feedback on performance. ${ }^{66}$ Most pediatric resuscitation events are rare, and few health care providers can master the critical skills (ie, endotracheal intubation, chest compressions, etc) without frequent practice and feedback. Deliberate practice with simulation allows pediatric health care providers to repeat desired procedures in a safe controlled setting and plays an important role in preparing them for critical events.
Hunt et $\mathrm{al}^{67}$ report that "rapid cycle deliberate practice" focused on procedural and teamwork skills was associated with improvement in performance in management of pediatric cardiopulmonary arrest by pediatric residents. After simulation-based training with deliberate practice, improvement was demonstrated in several key CPR metrics during simulated scenarios. Deliberate practice was also associated with starting chest compressions within 1 minute of loss of pulse and defibrillating within 2 minutes for shockable rhythms. Cordero et $\mathrm{al}^{68}$ and Barry et $\mathrm{al}^{69}$ also reported that deliberate practice improved performance of neonatal resuscitation.

Current literature has shown the potential of deliberate practice in improving and maintaining psychomotor skills in pediatric health care providers. It can be effectively used for both novice and expert health care professionals, and should be thoughtfully integrated into the design of simulation-based resuscitation teaching.

\section{Feedback}

Feedback refers to specific information people receive about their performance intended to improve future performance..$^{70,71}$ Feedback can be either intrinsic (sensory-perceptual information that is a natural part of learning) or extrinsic (information to augment the intrinsic information). Feedback can come from difference sources (simulator, feedback device, colleagues, instructor) and can be delivered during (concurrent feedback) or after (terminal feedback) training. Feedback is critical to ensure effective learning in SBE.

Although feedback can work to enhance learning, it can also degrade learning if learners become dependent on the feedback. This could be explained by cognitive load theory. ${ }^{72}$ Humans have a limited attention capacity (working memory) such that they process finite amounts of information simultaneously. An increased amount of cognitive processing was required for learners to perform a task while receiving, interpreting, and responding to concurrent feedback. ${ }^{72}$ If feedback is given too frequently during simulation training, learners might focus their attention on feedback information only, rather than engage in cognitive processing essential for learning. Thus, concurrent feedback becomes the integral part of what is learned and learners might use it as "crutches". Terminal feedback, on the other hand, has been shown on average to enhance learning. ${ }^{73,74}$

\section{Real-time feedback devices}

Use of real-time feedback devices is a good example of concurrent feedback. Real-time CPR feedback devices provide 
visual and/or auditory feedback based on CPR quality during cardiac arrest, and have been shown to improve the quality of chest compressions when used during cardiac arrest events. ${ }^{75}$ However, the use of these devices is limited in the pediatric population due to cost consideration and selection of devices approved for clinical use in infant and children. ${ }^{76}$ In a systematic review in 2009 , Yeung et $\mathrm{al}^{34}$ assessed the effect of feedback devices used during training on CPR skill acquisition and retention. Four studies have looked at CPR skill retention. ${ }^{77-80}$ Within these four studies, results of real-time feedback were mixed, Spooner et $a^{80}$ and Becker et $\mathrm{al}^{78}$ showed a significant effect of real-time feedback on 6-month skill retention. Some recent studies by Allan et al ${ }^{81}$ and Mpotos et $\mathrm{al}^{82}$ also showed that CPR training with audiovisual feedback device improved skill acquisition and retention.

Use of real-time feedback devices is effective in improving CPR skill acquisition and retention. Health educators should consider using them for CPR training. The principle of real-time feedback applies not only on CPR training, but also for all psychomotor skills training.

\section{Debriefing}

Debriefing, as a mean of terminal feedback, has been identified as the most important part of simulation-based training. A recent systematic review ${ }^{83}$ revealed that simulation with debriefing, when compared with no intervention, has a favorable effect on all translational outcomes. Although research related to debriefing is growing, literature related to debriefing for pediatric resuscitation is limited. A randomized trial ${ }^{57}$ demonstrated that scripted debriefing improved knowledge and team leader behavior performance, when compared with nonscripted debriefing. Following this trial, a scripted debriefing tool was developed using "Gather-Analysis-Summarize (GAS)" model ${ }^{84}$ and incorporated into the American Heart Association PALS instructor materials. Sawyer et $\mathrm{al}^{85}$ conducted a randomized trial to compare video-assisted debriefing versus oral debriefing alone on neonatal resuscitation training. NRP performance score improved significantly in both group, but video-assisted debriefing does not seem to provide extra benefit to oral debriefing alone. The result was consistent with previous nonpediatric studies, although it was limited by a small sample size. Other clinical research has also shown that structured debriefing after cardiac arrest improves return of spontaneous circulation ${ }^{35}$ and neurologic outcome ${ }^{36}$ of real patients. These studies demonstrate the immense potential of debriefing as a powerful quality improvement and educational tool, particularly when coupled with structured facilitation and objective data to help inform the educational process.

\section{Future directions}

Although simulation research is evolving, there are still several research gaps that help to inform the future direction of pediatric simulation research. First, there is a lack of research assessing actual patient outcomes. SBE has been shown to improve the satisfaction of leaners and skill performance in the simulated environment, but the ultimate purpose of SBE is to improve the patient outcomes in real clinical world. As such, future studies should aim to assess process and patient outcomes in the real clinical environment. Second, little is known about how the various aspects of realism influence learning and patient outcomes after SBE. Future research should be conducted to identify how various aspects of realism can be tailored to the learner type, learning objective, and learning environment in order to best optimize outcomes. Third, little is known about how simulation should be optimally used for summative assessment. To date, simulation has been primarily used for the purpose of teaching. However, the simulated environment could also function as a standardized setting to assess team as well as individual performance for resuscitation-related behaviors or tasks. For example, the incorporation of simulation-based resuscitation scenarios into Objective Standardized Clinical Exams (OSCE) represents one possible method of simulation-based assessments for acute care specialties. Future work can help to define how simulation-based summative assessment can be used to improve provider performance and patient outcomes from resuscitation events. Last, but not the least, there is a scarcity of research assessing the cost-effectiveness of SBE for resuscitation training. The equipment and maintenance of a simulation lab is expensive. Future research should not only define the optimal means of SBE for resuscitation, but also explore cost-benefit analysis for the same SBE interventions.

\section{Conclusion}

SBE is widely used in teaching neonatal resuscitation, pediatric resuscitation, CRM, airway management, CPR skills, and other resuscitation-related procedural skills. When using simulation to teach resuscitation-related knowledge, skills, and behaviors, health care educators should consider the use of HFS, distributed practice, deliberate practice, and feedback to help achieve optimal learning outcomes. Debriefing is a vital component of simulation-based resuscitation education, particularly when paired with structured facilitation and 
objective data to help learners with the acquisition of knowledge, skills, and behaviors.

\section{Disclosure}

The authors report no conflicts of interest in this work.

\section{References}

1. Nadel F, Lavelle J, Fein J, et al. Assessing pediatric senior residents' training in resuscitation: fund of knowledge, technical skills, and perception of confidence. Pediatr Emerg Care. 2000;16:73-76.

2. Cheng A, Lang TR, Starr SR, Pusic M, Cook DA. Technology-enhanced simulation and pediatric education: a meta-analysis. Pediatrics. 2014;133(5):e1313-e1323.

3. Cheng A, Auerbach M, Hunt EA, et al. Designing and conducting simulation-based research. Pediatrics. 2014;133(6):1091-1101. doi:10.1542/peds.2013-3267.

4. Rakshasbhuvankar AA, Patole SK. Benefits of simulation based training for neonatal resuscitation education: a systematic review. Resuscitation. 2014;85(10):1320-1323.

5. Kaczorowski J, Levitt C, Hammond M, et al. Retention of neonatal resuscitation skills and knowledge: a randomized controlled trial. Fam Med. 1998;30:705-711.

6. Arnold J. Neonatal Resuscitation Program comes of age. J Pediatr. 2011;159:357-358.

7. Cavaleiro A, Guimaraes H, Calheiros F. Training neonatal skills with simulators? Acta Paediatr. 2009;98:636-639.

8. Lee M, Brown L, Bender J, et al. A medical simulation-based educational intervention for emergency medicine residents in neonatal resuscitation. Acad Emerg Med. 2012;19:577-585.

9. Weiner G, Menghini K, Zaichkin J, et al. Self-directedversus traditional classroom training for neonatal resuscitation. Pediatrics. 2011;127:713-719.

10. Curran V, Aziz K, Young S, Bessell C. Evaluation of the effect of a computerized training simulator (ANAKIN) on retention of neonatal resuscitation skills. Teach Learn Med. 2004;16:157-164.

11. Draycott T, Sibanda T, Owen L, et al. Does training in obstetric emergencies improve neonatal outcome? BJOG. 2006;113:177-182.

12. Eppich WJ, Nypaver MM, Mahajan P, et al. The role of high-fidelity simulation in training pediatric emergency medicine fellows in the United States and Canada. Pediatr Emerg Care. 2013;29(1):1-7.

13. Nishisaki A, Hales R, Biagas K, et al. A multi-institutional high-fidelity simulation "boot camp" orientation and training program for first year pediatric critical fellows. Pediatr Crit Care Med. 2009;10:157-162.

14. Kane J, Pye S, Jones A. Effectiveness of a simulation-based education program in a pediatric cardiac intensive care unit. $J$ Pediatr Nurs. 2011;26:287-294.

15. Stocker M, Allen $M$, Pool N, et al. Impact of an embedded simulation team training programme ina pediatric intensive care unit: a prospective, singlecentre, longitudinal study. Intensive Care Med. 2012;38:99-104.

16. Hunt EA, Vera K, Diener-West M, et al. Delays and errors in cardiopulmonary resuscitation and defibrillation by pediatric residents during simulated cardiopulmonary arrests. Resuscitation. 2009;80(7):819-825.

17. Coolen E, Draaisma J, Hogeveen M, et al. Effectiveness of highfidelity video-assisted real-time simulation: a comparison of three training methods for acute pediatric emergencies. Int $J$ Pediatr. 2012;2012:709569.

18. Donoghue A, Durbin D, Nadel F, et al. Effect of high-fidelity simulation on Pediatric Advanced Life Support training in pediatric house staff: a randomized trial. Pediatr Emerg Care. 2009;25(3):139-144.

19. Donoghue A, Durbin D, Nadel F, Stryjewski G, Kost S, Nadkarni V. Perception of realism during mock resuscitation by pediatric housestaff: the impact of simulated physical features. Simul Healthc. 2010;5: $16-20$.
20. Gaies MG, Landrigan CP, Hafler JP, Sandora TJ. Assessing procedural skills training in pediatric residency programs. Pediatrics. 2007; 120(4):715-722.

21. Sudikoff SN, Overly FL, Shapiro MJ. High-fidelity medical simulation as a technique to improve pediatric residents' emergency airway management and teamwork. Pediatr Emerg Care. 2009;25(10): 651-656.

22. Nishisaki A, Donoghue A, Colborn S, et al. Effect of Just-in-time simulation training on tracheal intubation procedure safety in the pediatric intensive care unit. Anesthesiology. 2010;113:214-223.

23. Nishisaki A, Nguyen J, Colborn S, et al. Evaluation of multidisciplinary simulation training on clinical performance and team behavior during tracheal intubation procedures in a pediatric intensive care unit. Pediatr Crit Care Med. 2011;12(4):406-414.

24. Finan E, Bismilla Z, Campbell C, Leblanc V, Jefferies A, Whyte HE. Improved procedural performance following a simulation training session may not be transferable to the clinical environment. $J$ Perinatol. 2012;32(7):539-544.

25. Schebesta K, Hupfl M, Ringl H, et al. A comparison of paediatric airway anatomy with the SimBaby high-fidelity patient simulator. Resuscitation. 2011;82(4):468-472.

26. Herlitz J, Svensson L, Holmberg S, et al. Efficacy of bystander CPR: intervention by lay people and by health care professionals. Resuscitation. 2005;66(3):291-295.

27. Vadeboncoeur T, Stolz U, Panchal A, et al. Chest compression depth and survival in out-of-hospital cardiac arrest. Resuscitation. 2014;85(2): 182-188.

28. Meaney PA, Bobrow BJ, Mancini ME, et al. Cardiopulmonary resuscitation quality: improving cardiac resuscitation outcomes both inside and outside the hospital: a consensus statement from the American Heart Association. Circulation. 2013;128(4):417-435.

29. Winchell SW, Safar P. Resuscitation, teaching and testing lay and paramedical personnel in cardiopulmonary. Anesth Analg. 1966;45: 441-449.

30. Cheng A, Brown L, Duff J, et al. Improving CardioPulmonary Resuscitation with a CPR Feedback Device And Refresher Simulations (CPRCARES Study): a multicenter, randomized trial. JAMA Pediatr. 2015;169(2):137-144.

31. Sutton RM, Niles D, Nysaether J, et al. Quantitative analysis of CPR quality during in-hospital resuscitation of older children and adolescents. Pediatrics. 2009;124(2):494-499.

32. Niles D, Sutton R, Donoghue A, et al. Rolling refreshers: a novel approach to maintain CPR psychomotor skill competence. Resuscitation. 2009;80:909-912.

33. Sutton RM, Niles D, Meaney PA, et al. Low-dose, high-frequency CPR training improves skill retention of in-hospital pediatric providers. Pediatrics. 2011;128(1):e145-e151.

34. Yeung J, Meeks R, Edelson D, Gao F, Soar J, Perkins GD. The use of CPR feedback/prompt devices during training and CPR performance: a systematic review. Resuscitation. 2009;80(7):743-751.

35. Edelson D, Litzinger B, Arora V, et al. Improving in-hospital cardiac arrest process and outcomes with performance debriefing. Arch Intern Med. 2008;168(10):1063-1069.

36. Wolfe $\mathrm{H}$, Zebuhr $\mathrm{C}$, Topjian AA, et al. Interdisciplinary ICU cardiac arrest debriefing improves survival outcomes. Crit Care Med. 2014;42(7):1688-1695.

37. Al-Qadhi S, Pirie J, Constas N, Corrin M, Ali M. An innovative pediatric chest tube insertion task trainer simulation: a technical report and pilot study. Simul Healthc. 2014;9(5):319-324.

38. Gupta A, Ramasethu J. An innovative neoanimal simulation trainer for chest tube insertion in neonates. Pediatrics. 2014;134(3):e798-e805.

39. Macnab A, Macnab M. Teaching pediatric procedures: the Vancouver model for instructing Seldinger's technique of central venous access via the formral vein. Pediatrics. 1999;103:E8.

40. Gerard JM, Thomas SM, Germino KW, Street MH, Burch W, Scalzo AJ. The effect of simulation on PALS skills among family medicine residents. Fam Med. 2011;43(6):392-399. 
41. Mikrogianakis A, Kam A, Silver S, et al. Telesimulation: an innovative and effective tool for teaching novel intraosseous insertion techniques in developing countries. Acad Emerg Med. 2011;18(4):420-427.

42. Gaies M, Morris S, Hafler J, et al. Reforming procedural skills training for pediatric residents: a randomized, interventional trial. Pediatrics. 2009;124:610-619.

43. Cheng A, Donoghue A, Gilfoyle E, Eppich W. Simulation-based crisis resource management training for pediatric critical care medicine. Pediatr Crit Care Med. 2012;13(2):197-203.

44. Thomas E, Taggart B, Crandell S, et al. Teaching teamwork during the Neonatal Resuscitation Program: a randomized trial. J Perinatol. 2007;27:409-414

45. Gilfoyle E, Gottesman R, Razack S. Development of a leadership skills worksho pin paediatric advanced resuscitation. Med Teach. 2007;29:e276-e283.

46. Figueroa M, Sepanski R, Goldberg S, Shah S. Improving teamwork, confidence, and collaboration among members of a pediatric cardiovascular intensive care unit multidisciplinary team using simulation-based team training. Pediatr Cardiol. 2013;34:612-619.

47. Bank I, Snell L, Bhanji F. Pediatric crisis resource management training improves emergency medicine trainees' perceived ability to manage emergencies and ability to identify teamwork errors. Pediatr Emerg Care. 2014;30(12):879-883.

48. Blackwood J, Duff JP, Nettel-Aguirre A, Djogovic D, Joynt C. Does teaching crisis resource management skills improve resuscitation performance in pediatric residents? Pediatr Crit Care Med. 2014; 15(4):1-7

49. Cook DA, Hatala R, Brydges R, et al. Technology-enhanced simulation for health professions education: a systematic review and meta-analysis. JAMA. 2011;30(9):978-988.

50. Cook DA, Hamstra SJ, Brydges R, et al. Comparative effectiveness of instructional design features in simulation-based education: systematic review and meta-analysis. Med Teach. 2013;35(1):e867-e898.

51. Merriam S, Caffarella R, Baumgartner L. Learning in Adulthood. A Comprehensive Guide. 3rd ed. San Francisco, CA: Jossey-Bass; 2007:275-295.

52. Tulving E, Thomson DM. Encoding specifi city and retrieval processes in episodic memory. Psychol Rev. 1973;80(5):352-373.

53. Torre D, Daley B, Sebastian J, et al. Overview of current learning theories for medical educators. Am J Med. 2006;119(10):903-907.

54. Campbell D, Barozzino T, Farrugia M, Sgro M. High-fidelity simulation in neonatal resuscitation. Paediatr Child Health. 2009;14(1): 19-23.

55. Thomas EJ, Williams AL, Reichman EF, Lasky RE, Crandell S, Taggart WR. Team training in the neonatal resuscitation program for interns: teamwork and quality of resuscitations. Pediatrics. 2010;125(3):539-546.

56. Finan E, Bismilla Z, Whyte HE, Leblanc V, McNamara PJ. Highfidelity simulator technology may not be superior to traditional lowfidelity equipment for neonatal resuscitation training. J Perinatol. 2012;32(4):287-292.

57. Cheng A, Hunt EA, Donoghue A, et al. Examining pediatric resuscitation education using simulation and scripted debriefing: a multicenter randomized trial. JAMA Pediatr. 2013;167(6):528-536.

58. Butler K, Veltre D, Drady D. Implementation of active learning pedagogy comparing low-fidelity simulation versus highfidelity simulation in pediatric nursing education. Clin Simul Nurs. 2009;5(4):e129-e136

59. Bultas MW, Hassler M, Ercole PM, Rea G. Effectiveness of highfidelity simulation for pediatric staff nurse education. Pediatr Nurs. 2014;40(1):27-32.

60. Malec J, Torsher L, Dunn W, et al. The mayo high performance team work scale: reliability and validity for evaluating key crew resource management skills. Simul Healthc. 2007;2(1):4-10.

61. Raman M, McLaughlin K, Violato C, Rostom A, Allard JP, Coderre S. Teaching in small portions dispersed over time enhances long-term knowledge retention. Med Teach. 2010;32(3):250-255.
62. Verkoeijen P, Rikers R, Schmidt HG. Limitations to the spacing effect: demonstration of an inverted u-shaped relationship between interrepetition spacing and free recall. Exp Psychol. 2005;52(4):257-263.

63. Kurosawa $H$, Ikeyama $T$, Achuff $P$, et al. A randomized, controlled trial of in situ pediatric advanced life support recertification ("pediatric advanced life support reconstructed") compared with standard pediatric advanced life support recertification for ICU frontline providers. Crit Care Med. 2014;42:610-618.

64. Ernst KD, Cline WL, Dannaway DC, et al. Weekly and consecutive day neonatal intubation training: comparable on a pediatrics clerkship. Acad Med. 2014;89(3):505-510.

65. Ericsson K. Deliberate practice and the acquisition and maintenance of expert performance in medicine and related domains. Acad Med. 2004;79(Suppl 10):70-81.

66. Issenberg S, McGaghie W, Petrusa E, Lee Gordon D, Scalese RJ. Features and uses of high-fidelity medical simulations that lead to effective learning: a BEME systematic review. Med Teach. 2005;27: 10-28.

67. Hunt EA, Duval-Arnould JM, Nelson-McMillan KL, et al. Pediatric resident resuscitation skills improve after "rapid cycle deliberate practice" training. Resuscitation. 2014;85(7):945-951.

68. Cordero L, Hart BJ, Hardin R, Mahan JD, Nankervis CA. Deliberate practice improves pediatric residents' skills and team behaviors during simulated neonatal resuscitation. Clin Pediatr (Phila). 2013;52:747-752.

69. Barry JS, Gibbs MD, Rosenberg AA. A delivery room-focused education and deliberate practice can improve pediatric resident resuscitation training. J Perinatol. 2012;32(12):920-926.

70. Ende J. Feedback in clinical medical education. JAMA. 1983;250: 777-781.

71. Schmidt R, Lee T, editors. Motor Control and Learning: A Behavioural Emphasis. 3rd ed. Champaign, IL: Human Kinetics; 1999.

72. Sweller J, van Merrienboer J, Paas F. Cognitive architecture and instructional design. Educ Psychol Rev. 1998;10:251-296.

73. Xeroulis G, Park J, Moulton C, et al. Teaching suturing and knot-tying skills to medical students: a randomized controlled study comparing computer-based video instruction and expert feedback. Surgery. 2007;141:442-449.

74. Walsh C, Ling S, Wang C, Carnahan H. Concurrent versus terminal feedback: it may be better to wait. Acad Med. 2009;84(10 Suppl): S54-S57.

75. Kirkbright S, Finn J, Tohira H, Bremner A, Jacobs I, Celenza A. Audiovisual feedback device use by health care professionals during CPR: a systematic review and meta-analysis of randomised and nonrandomised trials. Resuscitation. 2014;85(4):460-471.

76. Edelson DP, Yuen TC, Mancini ME, et al. Hospital cardiac arrest resuscitation practice in the United States: a nationally representative survey. J Hosp Med. 2014;9(6):353-357.

77. Wik L, Myklebust H, Auestad B, Steen P. Retention of basic life support skills 6 months after training with an automated voice advisory manikin system without instructor involvement. Resuscitation. 2002;52:373-379.

78. Beckers SK, Skorning MH, Fries M, et al. CPREzy improves performance of external chest compressions in simulated cardiac arrest. Resuscitation. 2007;72(1):100-107.

79. Isbye DL, Høiby P, Rasmussen MB, et al. Voice advisory manikin versus instructor facilitated training in cardiopulmonary resuscitation. Resuscitation. 2008;79(1):73-81.

80. Spooner BB, Fallaha JF, Kocierz L, Smith CM, Smith SCL, Perkins GD. An evaluation of objective feedback in basic life support (BLS) training. Resuscitation. 2007;73(3):417-424

81. Allan KS, Wong N, Aves T, Dorian P. The benefits of a simplified method for CPR training of medical professionals: a randomized controlled study. Resuscitation. 2013;84(8):1119-1124.

82. Mpotos N, Yde L, Calle P, et al. Retraining basic life support skills using video, voice feedback or both: a randomised controlled trial Resuscitation. 2013;84(1):72-77. 
83. Cheng A, Eppich W, Grant V, Sherbino J, Zendejas B, Cook DA. Debiefing for technology-enhanced simulation: a systematic review and meta-analysis. Med Educ. 2014;48:657-666.

84. Cheng A, Rodgers DL, van der Jagt É, Eppich W, O’Donnell J. Evolution of the Pediatric Advanced Life Support course. Pediatr Crit Care Med. 2012;13(5):589-595.
85. Sawyer T, Sierocka-Castaneda A, Chan D, Berg B, Lustik M, Thompson M. The effectiveness of video-assisted debriefing versus oral debriefing alone at improving neonatal resuscitation performance: a randomized trial. Simul Healthc. 2012;7(4):213-221.

\section{Publish your work in this journal}

Advances in Medical Education and Practice is an international, peerreviewed, open access journal that aims to present and publish research on Medical Education covering medical, dental, nursing and allied health care professional education. The journal covers undergraduate education, postgraduate training and continuing medical education including emerging trends and innovative models linking education, research, and health care services. The manuscript management system is completely online and includes a very quick and fair peer-review system. Visit http://www.dovepress.com/testimonials.php to read real quotes from published authors.

Submit your manuscript here: http://www.dovepress.com/advances-in-medical-education-and-practice-journal 